\title{
Editorial
}

\section{Palladium-Catalyzed Reactions}

\author{
Nicola Della Ca' (D)
}

check for updates

Citation: Della $\mathrm{Ca}^{\prime}, \mathrm{N}$.

Palladium-Catalyzed Reactions. Catalysts 2021, 11, 588. https:// doi.org/10.3390/catal11050588

Received: 6 April 2021

Accepted: 9 April 2021

Published: 30 April 2021

Publisher's Note: MDPI stays neutral with regard to jurisdictional claims in published maps and institutional affiliations.

Copyright: (C) 2021 by the author. Licensee MDPI, Basel, Switzerland. This article is an open access article distributed under the terms and conditions of the Creative Commons Attribution (CC BY) license (https:// creativecommons.org/licenses/by/ $4.0 /)$.
Department of Chemistry, Life Sciences and Environmental Sustainability (SCVSA), University of Parma, Parco Area delle Scienze 17/ A, 43124 Parma, Italy; nicola.dellaca@unipr.it

Palladium is probably the most versatile and exploited transition metal in catalysis due to its capability to promote a myriad of organic transformations both at laboratory and industrial scales (alkylation, arylation, cyclization, hydrogenation, oxidation, isomerization, cross-coupling, cascade, radical reactions, etc.). Natural alkaloids, bioactive compounds, pharmaceutical agents, agrochemicals and specialty polymers can be efficiently accessed by means of palladium catalysts. Despite impressive achievements in catalysis, palladium chemistry continues to be enriched with new, exciting discoveries every day.

Although intensive efforts are still made to develop novel and more efficient palladiumbased catalytic systems, and to expand the number of accessible transformations, more and more attention is being devoted to increasing the sustainability of the processes. In this respect, the articles collected in the present Special Issue focus on recent advances in homogeneous and heterogeneous palladium-catalyzed reactions, including: (1) the use of palladium in combination with other metals, (2) palladium-catalyzed cross-coupling reactions, (3) the development of new ligands for palladium-based catalysts, and (4) palladium-based catalysts for the synthesis of bulk and fine chemicals. It consists of original research articles as well as topical reviews.

Amines are ubiquitous motifs in biologically active compounds and useful building blocks in organic synthesis. The hydroamination strategy is one of the most attractive approaches to building $\mathrm{C}-\mathrm{N}$ bonds. In this context, palladium catalysts have demonstrated their large applicability and versatility. Della $\mathrm{Ca}^{\prime}$ and coworkers have developed a simple and versatile protocol for the regioselective hydroamination of arylacetylenes with anilines using $\mathrm{PdI}_{2}$ without any additional ligand or additive [1]. In this way, a variety of secondary aromatic amines can be readily accessed.

The synthetic importance of Suzuki-Miyaura cross-coupling is widely recognized. New pyrazole-containing ligands, analogues of DPEphos and Xantphos, have been synthesized, isolated in good yields and subsequently tested through Suzuki-Miyaura crosscoupling by Monteiro and coworkers [2]. The symmetrical bis-pyrazolyl and the hybrid imidazolyl-pyrazolyl analogues were found to be most active in the reaction of aryl halides with aryl boronic acids. In particular, moderate yields were achieved by employing activated aryl chlorides.

With the idea to develop more efficient and recyclable heterogeneous catalytic systems, a new method, based on the use of Methoxy Polyene Glycol (PEG-OMe), was developed by Xie, Zhang, Gao and coworkers to immobilize Pd/Cu bimetallic nanoparticles on activated carbon [3]. The obtained palladium/copper catalysts were tested in Sonogashira coupling reactions. The highest activity, also with aryl bromides as starting materials, was shown by Pd/Cu@AC prepared in a PEG-OMe 500. The recyclability of the catalyst was successfully demonstrated.

The use of polysaccharides derived from renewable sources as supports for metal catalysts is recently gaining an increasing interest in the field. The review of Wolfson and Levy-Ontman describes the recent advances related with the employment of natural polysaccharide matrices as supports for palladium complexes, and the application of the resulting heterogeneous catalytic systems in the Suzuki cross-coupling [4]. 
Palladium-based catalysts can be successfully employed in the synthesis of industrially relevant compounds. The review of Beccalli et al. [5] describes palladium-catalyzed reactions aimed at the synthesis of benzodiazepines that display a wide range of pharmaceutical applications. Different palladium (0) and palladium (II) catalysts have been found to catalyze complex reaction sequences, including hydroamination, amination, $\mathrm{C}-\mathrm{H}$ arylation, $\mathrm{N}$-arylation, and the Buchwald-Hartwig reaction.

The electrocatalytic hydrodehalogenation of chlorophenols has been regarded as an attractive method for the removal of halogen atoms in chlorine-containing aromatic hydrocarbons, which represents a big issue from an environmental point of view. Wei et al. have recently prepared a bimetallic electrode composed of $\mathrm{Pd}-\mathrm{Ag}$, which was applied to the electrocatalytic hydrodechlorination of 4-chlorophenol in water [6]. This new electrode, obtained via chemical deposition, exhibits high performances with low Pd loadings, and, for these reasons, industrial application prospects are expected.

Palladium catalysts have been found to promote a wide variety of oxidation reactions, both under homogeneous and heterogeneous conditions. The review article of Muzart and Le Bras is an exciting look into palladium-catalyzed oxidation reactions [7], starting with light-promoted reactions and going through other palladium-catalyzed oxidations (allyl oxidation, alcohol oxidation, etc.), each time with insights on the reaction mechanism.

The cooperation of palladium with another metal often provides huge benefits in catalysis. An example is the hydrotalcite-supported $\mathrm{Ag} / \mathrm{Pd}$ bimetallic nanocluster catalyst, which has been developed by Karanjit et al. for the efficient and environmentally friendly oxidation of alcohols [8]. The $\mathrm{Ag} / \mathrm{Pd}$ bimetallic catalyst demonstrated also to catalyze the one-pot cross-aldol condensation in water. A broad scope of $\alpha, \beta$-unsaturated ketones and the reusability of the catalyst was successfully achieved.

Catalytic oxidation represents one of the most efficient and environmentally friendly methodologies to eliminate volatile organic compounds (VOCs). Catalytic materials based on the combination of rare earth elements and palladium, obtained via a high-temperature solution-phase reduction method, were synthesized and tested for the complete oxidation of toluene [9]. These heterogeneous materials developed by Zuo and coworkers have high resistance to water and chlorine poisoning.

A carbide-modified $\mathrm{Pd}$ on $\mathrm{ZrO}_{2}$ catalyst was recently developed by Klötzer and coworkers [10] for the dry reforming of methane (DRM), which is potentially able to simultaneously reduce the two major climate-harming greenhouse gases, methane and carbon dioxide. In the field of methane oxidation over palladium oxide-based catalysts, Deutschmann et al., with a combined experimental and modeling approach [11], provided more insights on the water inhibition effect, which strongly inhibits methane oxidation.

Sinomenine is a natural alkaloid and commonly used as one of the bioactive drug components in the treatment of rheumatoid arthritis. Zhu and coworkers prepared various palladium-based materials and tested them in the extraction of sinomenine from Sinomenium acutum. The materials can be easily recovered and reused [12].

Finally, with the idea to reduce the palladium content in palladium nanoparticles (NPs), Kunal and Topps describe the latest advances in the preparation of nanocatalysts using microwave heating [13].

I would like to thank Keith Hohn, Editor-in-Chief, for the opportunity to organize this Special Issue, Caroline Zhan, Assistant Editor of this Special Issue, and the staff of the Catalysts Editorial Office for their significant support, encouragement, and patience. We would also like to thank the reviewers of the submitted manuscripts for their valuable recommendations, and the contributing authors for their hard work in revising their manuscripts in order to meet the high standards of this Special Issue.

Funding: This research received no external funding.

Conflicts of Interest: The authors declare no conflict of interest. 


\section{References}

1. Casnati, A.; Voronov, A.; Ferrari, D.G.; Mancuso, R.; Gabriele, B.; Motti, E.; Della Ca', N. PdI2 as a Simple and Efficient Catalyst for the Hydroamination of Arylacetylenes with Anilines. Catalysts 2020, 10, 176. [CrossRef]

2. Hussain, Z.; Schwalm, C.; Rambo, R.; Dias, R.; Stieler, R.; Monteiro, A. Synthesis of Mono- and Bis-Pyrazoles Bearing Flexible p-Tolyl Ether and Rigid Xanthene Backbones, and Their Potential as Ligands in the Pd-Catalysed Suzuki-Miyaura Cross-Coupling Reaction. Catalysts 2019, 9, 718. [CrossRef]

3. Wei, Z.; Xie, Z.; Gao, L.; Wang, Y.; Sun, H.; Jian, Y.; Zhang, G.; Xu, L.; Yang, J.; Zhang, W.; et al. Highly Crystallized Pd/Cu Nanoparticles on Activated Carbon: An Efficient Heterogeneous Catalyst for Sonogashira Cross-Coupling Reaction. Catalysts 2020, 10, 192. [CrossRef]

4. Wolfson, A.; Levy-Ontman, O. Recent Developments in the Immobilization of Palladium Complexes on Renewable Polysaccharides for Suzuki-Miyaura Cross-Coupling of Halobenzenes and Phenylboronic Acids. Catalysts 2020, 10, 136. [CrossRef]

5. Christodoulou, M.S.; Beccalli, E.M.; Giofrè, S. Palladium-Catalyzed Benzodiazepines Synthesis. Catalysts 2020, 10, 634. [CrossRef]

6. Wei, X.; Zeng, L.; Lu, W.; Miao, J.; Zhang, R.; Zhou, M.; Zhang, J. A Polypyrrole-Modified Pd-Ag Bimetallic Electrode for the Electrocatalytic Reduction of 4-Chlorophenol. Catalysts 2019, 9, 931. [CrossRef]

7. Le Bras, J.; Muzart, J. The Reims Journey Towards Discovery and Understanding of Pd-Catalyzed Oxidations. Catalysts 2020, $10,111$. [CrossRef]

8. $\quad$ Karanjit, S.; Tamura, A.; Kashihara, M.; Ushiyama, K.; Shrestha, L.K.; Ariga, K.; Nakayama, A.; Namba, K. Hydrotalcite-Supported $\mathrm{Ag} / \mathrm{Pd}$ Bimetallic Nanoclusters Catalyzed Oxidation and One-Pot Aldol Reaction in Water. Catalysts 2020, 10, 1120. [CrossRef]

9. Chen, Z.; Situ, D.; Zheng, J.; Cheng, Z.; Wang, Z.; Zuo, S. Y-Modified MCM-22 Supported PdOx Nanocrystal Catalysts for Catalytic Oxidation of Toluene. Catalysts 2019, 9, 902. [CrossRef]

10. Köpfle, N.; Ploner, K.; Lackner, P.; Götsch, T.; Thurner, C.; Carbonio, E.; Hävecker, M.; Knop-Gericke, A.; Schlicker, L.; Doran, A.; et al. Carbide-Modified Pd on $\mathrm{ZrO}_{2}$ as Active Phase for $\mathrm{CO}_{2}$-Reforming of Methane-A Model Phase Boundary Approach. Catalysts 2020, 10, 1000. [CrossRef]

11. Keller, K.; Lott, P.; Stotz, H.; Maier, L.; Deutschmann, O. Microkinetic Modeling of the Oxidation of Methane Over PdO Catalysts-Towards a Better Understanding of the Water Inhibition Effect. Catalysts 2020, 10, 922. [CrossRef]

12. Zhu, Y.; Bai, Z. Pd-Ce/ZIF-8 Nanocomposite for Catalytic Extraction of Sinomenine from Sinomenium acutum. Catalysts 2020, 10, 174. [CrossRef]

13. Kunal, P.; Toops, T.J. A Review of Microwave-Assisted Synthesis-Based Approaches to Reduce Pd-Content in Catalysts. Catalysts 2020, 10, 991. [CrossRef] 